\title{
Projections of hydrofluorocarbon (HFC) emissions and the resulting global warming based on recent trends in observed abundances and current policies
}

5 Guus J.M. Velders ${ }^{1,2}$, John S. Daniel ${ }^{3}$, Stephen A. Montzka ${ }^{4}$, Isaac Vimont ${ }^{4,5}$, Matthew Rigby $^{6}$, Paul B. Krummel ${ }^{7}$, Jens Muhle ${ }^{8}$, Simon O'Doherty ${ }^{6}$, Ronald G. Prinn ${ }^{9}$, Ray F. Weiss $^{8}$, and Dickon Young ${ }^{6}$

${ }^{1}$ National Institute for Public Health and the Environment (RIVM), PO Box 1, 3720 BA

Bilthoven, the Netherlands

${ }^{2}$ Institute for Marine and Atmospheric Research Utrecht (IMAU), Utrecht University, Utrecht, the Netherlands

${ }^{3}$ Chemical Sciences Laboratory, National Oceanic and Atmospheric Administration, Boulder, Colorado, USA

$15{ }^{4}$ Global Monitoring Laboratory, National Oceanic and Atmospheric Administration, Boulder, Colorado, USA

${ }^{5}$ Cooperative Institute for Research in Environmental Sciences, University of Colorado, Boulder, Colorado, USA

${ }^{6}$ School of Chemistry, University of Bristol, Bristol, UK

$20{ }^{7}$ Climate Science Centre, CSIRO Oceans and Atmosphere, Aspendale, Victoria, Australia

${ }^{8}$ Scripps Institution of Oceanography, University of California San Diego, La Jolla,

California, USA

${ }^{9}$ Center for Global Change Science, Massachusetts Institute of Technology, Cambridge, Massachusetts, USA

Correspondence to: Guus J.M. Velders (guus.velders@ rivm.nl) 


\begin{abstract}
30 The emissions of hydrofluorocarbons (HFCs) have increased significantly in the past two decades, primarily as a result of the phaseout of ozone depleting substances under the Montreal Protocol and the use of HFCs as their replacements. Projections from 2015 showed large increases in $\mathrm{HFC}$ use and emissions in this century in the absence of regulations, contributing up to $0.5{ }^{\circ} \mathrm{C}$ to global surface warming by 2100. In 2019, the Kigali Amendment

35 to the Montreal Protocol came into force with the goal of limiting the use of HFCs globally, and currently, regulations to limit the use of HFCs are in effect in several countries. Here, we analyze trends in HFC emissions inferred from observations of atmospheric abundances and compare them with previous projections. Total $\mathrm{CO}_{2}$-eq inferred $\mathrm{HFC}$ emissions continue to increase through 2019 (to about $0.8 \mathrm{GtCO}_{2}$-eq $\mathrm{yr}^{-1}$ ) but are about $20 \%$ lower than previously

40 projected for 2017-2019, mainly because of lower global emissions of HFC-143a. This indicates that HFCs are used much less in industrial and commercial refrigeration (ICR) applications than previously projected. This is supported by data reported by the developed countries and lower reported consumption of HFC-143a in China. Because this time-period preceded the beginning of the Kigali controls, this reduction cannot be linked directly to the

45 provisions of the Kigali Amendment. However, it could indicate that companies transitioned away from the HFC-143a with its high global warming potential (GWP) for ICR applications, in anticipation of national or global mandates. A new HFC scenario is developed based on current trends in HFC use and current policies in several countries. These current policies reduce projected emissions in 2050 from the previously calculated 4.0-5.3 $\mathrm{GtCO}_{2}$-eq $\mathrm{yr}^{-1}$ to

$50 \quad 1.9-3.6 \mathrm{GtCO}_{2}$-eq $\mathrm{yr}^{-1}$. The provisions of the Kigali Amendment are projected to reduce the emissions further to $0.9-1.0 \mathrm{GtCO}_{2}$-eq $\mathrm{yr}^{-1}$ in 2050. Without current policies, HFCs would be projected to contribute $0.28-0.44{ }^{\circ} \mathrm{C}$ to the global surface warming in 2100 , compared to 0.14-0.31 ${ }^{\circ} \mathrm{C}$ with current policies, but without the Kigali Amendment. In contrast, the Kigali Amendment controls are expected to limit surface warming from HFCs to about $0.04{ }^{\circ} \mathrm{C}$ in 552100.
\end{abstract}

Keywords: Montreal Protocol; Kigali Amendment; radiative forcing; temperature; climate 


\section{Introduction}

60 Hydrofluorocarbons (HFCs) are largely used as alternatives for ozone-depleting substances, which are being phased out as a result of the provisions of the Montreal Protocol (UNEP, 2020). Consequently, large percentage increases have been observed in the emissions and atmospheric abundances of many HFCs since the beginning of this century (Montzka and Velders et al., 2018). HFCs do not deplete the ozone layer, but they are potent greenhouse

65 gases contributing to climate warming. Global projections from 2009 and 2015 anticipated large increases in HFC use and emissions in the absence of regulations (Velders et al., 2015; Velders et al., 2009). Similar increases were suggested by other studies (Purohit et al., 2020; Gschrey et al., 2011;Purohit and Hoglund-Isaksen, 2017). The projected increase in emissions results in an increase in radiative forcing of the climate - leading to a potential contribution to global average surface warming of $0.3-0.5^{\circ} \mathrm{C}$ in 2100 (Montzka and Velders et al., 2018; Xu et al., 2013). In the EU, USA, and Japan, regulations to limit the use of HFCs were already in effect before the Kigali controls (EU, 2014, 2006;METI, 2015;US-EPA, 2020). In 2016, the Kigali Amendment to the Montreal Protocol was agreed to and aims to phase down the production and consumption of HFCs globally, starting in 2019 (UNEP,

75 2020). Following the provisions of this Amendment, HFC emissions were projected to be constrained and the surface warming is expected to be limited to less than $0.1^{\circ} \mathrm{C}$ in 2100 (Montzka and Velders et al., 2018).

In 2015, global projections of HFC use, emissions, mixing ratios, and radiative forcing were reported based on observation-based estimates of emissions through 2012 and observations of mixing ratios up to 2013 (Velders et al., 2015). Since then, HFC emissions inferred from observed mixing ratios have been reported for several countries, such as the United Kingdom up to 2018 (Manning et al., 2021), the United States from 2008 through 2014 (Hu et al., 2015; Hu et al., 2017), China for 2011-2017 (Yao et al., 2019), and India for 2016 (Say et al., 2019). Also, reviews of bottom-up and top-down emission estimates of HFCs have recently been published by Montzka and Velders et al. (2018) and Flerlage et al. (2021). Historical HFC consumption data for several use sectors in China have been reported by Li et al. (2019) and Fang et al. (2016) and for Chinese room air conditioning (AC) specifically by Liu et al. (2019).

In this paper, we examine how the global 2015 scenario from Velders et al. (2015) compares with trends in emissions inferred from atmospheric observations since 2013, to investigate if there are indications of reduced use or slower increase in use of HFCs, e.g., from national 
regulations or the Kigali Amendment or the anticipation of the Kigali controls. Based on this comparison, updated historical HCFC consumption data reported to UNEP, HFC use derived from data reported by developed countries to the UNFCCC, and HFC use data reported for

95 China, we develop new HFC projections and discuss differences with the 2015 scenarios. Apart from the new and updated atmospheric observational information, the current projections also differ from the baseline projections of Velders et al. (2015), because they follow the HFC phasedown policies currently in place in the EU, USA, and Japan.

The structure is as follows. First, in Sect. 2.1 to 2.5 the observations and methods used to infer global emissions are described, historical HFC and HCFC consumption are discussed, HFC use and emission scenarios are presented, and the model to project HFC emissions and the model assumptions are given. Second, in Sect. 3.1 to 3.3 the 2015 baseline scenario is compared with recent trends in global emissions inferred from observations. Third, the results of the new "current policy" scenario and of the impact of the Kigali Amendment on

105 emissions are presented in Sect. 3.4 and 3.5, followed by the effects of hypothetical zero production and emissions scenarios in Sect. 3.6. Finally, the effects of the new HFC scenarios on future surface warming are discussed in Sect. 3.7, followed by a discussion and conclusions of the results in Sect. 4.

\section{Methods}

\subsection{AGAGE and NOAA observations and inferred emissions}

HFC mixing ratios are measured by the Advanced Global Atmospheric Gases Experiment (AGAGE) (Prinn et al., 2018) and by the National Oceanographic and Atmospheric Administration (NOAA) Global Monitoring Laboratory GML) (Montzka et al., 2015) at various locations around the globe (see Caption Figure 1). The global and annual average

115 mixing ratios are used here to infer the global total annual emissions for the individual HFCs from 1990 to 2020 using a 1-box model of the atmosphere and constant prescribed HFC lifetimes as presented in WMO (2018) (see Sect. 2.5). The HFCs considered here are HFC32, HFC-125, HFC-134a, HFC-143a, HFC-152a, HFC-227ea, HFC-236fa, HFC-245fa, HFC$365 \mathrm{mfc}$, and HFC-43-10mee. These HFCs are used in large amounts for refrigeration and air 120 conditioning applications, foam blowing, as aerosol propellants, in fire suppression systems, and as solvents. HFC-23 is not considered here, since it has only very small intentional uses and its emissions originate mainly as a by-product from the production of HCFC-22 (Stanley 
et al., 2020); furthermore, the Kigali Amendment controls HFC-23 in a different manner than the other HFCs considered here.

\subsection{Historical HFC consumption}

The new scenarios start with reported historical consumption and assumptions for missing data using the same procedure as described in Velders et al. (2015). Historical consumption is based on: 1) HFC activity data and emissions per sector reported by developed countries to the United Nations Framework Convention on Climate Change (UNFCCC, 2021) up to 2018,

130 2) HCFC consumption data reported by developing countries to United Nations Environment (UNEP, 2021) up to 2019, and 3) global HFC emissions derived from global average HFC mixing ratio histories measured by the AGAGE and NOAA networks up to 2020 (see Sect. 2.1).

Annual consumption of individual HFCs per sector is derived from the UNFCCC (2021)

135 activity data as the change from one year to the next in the amounts of HFCs in stock plus the annual HFC emissions from manufacturing, stocks, disposal, and recovery. The derived consumption data, available for developed (Annex 1) countries only, is grouped in five regions: European Union (EU), USA, Japan, other countries of the Organization for Economic Co-operation and Development (OECD), and States of the former Soviet

140 Republics and Yugoslavia. Consumption for 12 separate use sectors is derived for each region (see Sect. 2.5). The data reported for Japan to the UNFCCC (2021) is augmented with consumption data for stationary air conditioning (AC) from their National Inventory report (NIES, 2020). Consumption data for other reporting OECD countries, only available for Australia, Canada, New Zealand, Norway, Switzerland, Iceland, and Turkey, is multiplied by

145 a factor of 1.05 (based on the ratio of the populations) to account for non-reporting OECD countries. Consumption data for States of the former Soviet Republics and Yugoslavia, only available for Russia, Ukraine, and Kazakhstan, is multiplied by a factor of 1.5 (population ratio) to account for other countries in this region.

Consumption data reported for developing countries is only available for China as reported

150 by Li et al. (2019) for 1995-2017. This consumption data takes into account import and export of HFCs and therefore represents the Chinese national HFC consumption. HFC consumption in most other developing countries started around 2013 following the first limits on the use of HCFCs in developing countries mandated by the Montreal Protocol. Some counties have reported HFC consumption data for 2018 to UNEP under the requirements of 
the Kigali Amendment, but since this data is still incomplete it is not used in the scenarios here. For India, consumption data is estimated from emissions inferred for 2016 by Say et al. (2019) and used in the scenarios. For other developing countries, HFC consumption data for 2013 to 2018 from the baseline scenario of Velders et al. (2015) is used here. These regions are Asian countries other than China and India, Middle and Southern Africa, Latin America, and Middle East and Northern Africa. HFC-134a consumption data for mobile air conditioning in developing countries (except China) is estimated from the number of cars in use, the average charge and lifetime of cars (see Velders et al. (2009) and Velders et al. (2015)).

From the UNFCCC (2021) data, emissions factors, i.e. the annual emissions as a fraction of

165 the banks, are derived per sector for the five developed countries/regions. The HFC consumption data from 1990 to 2018 are used in the aforementioned 1-box model of the global atmosphere, in combination with these emission factors and WMO (2018) lifetimes, to calculate annual emissions and mixing ratios. The consumption data is then increased or decreased (by applying a fixed scaling factor to each sector and region) so that the calculated

170 emissions match the emissions inferred from observations (see Sect. 2.1). This adjustment is applied since uncertainty in emissions derived from observed HFC mixing ratios are small (Montzka and Velders et al., 2018) and assumed to be smaller than emissions estimated from reported consumption data. The 2018 emissions from these calculations, which are used as a starting point for our projections, are therefore consistent with emissions derived from

175 observed atmospheric mixing ratios.

For some HFCs there is a large mismatch between total calculated emissions from reported or estimated consumption and emissions inferred from observed mixing ratios. This results from no reporting, or underreporting, of HFC consumption by developed countries to the UNFCCC and missing information from developing countries (Flerlage et al., 2021). To

180 obtain a good starting point for the scenarios, the consumption of these HFCs is scaled so that the calculated emissions match the emissions inferred from observations. Large mismatches are found for HFC-152a (extruded polystyrene (XPS) foam and aerosol use in the USA), HFC-227ea (fire protection and aerosol use in the USA), HFC-236fa (fire protection use in China), HFC-245fa (polyurethane (PUR) foam in the USA), HFC-365mfc (solvent use in the 185 EU), and HFC-41-10mee (solvent use in the EU and the USA). 


\section{3 "Current policy" scenario for future emissions}

Our scenario that is consistent with existing regional and national policies, excluding the Kigali Amendment, starts with the derived consumption totals from both developed and developing countries during 1990 to 2017. The total consumption in each year is adjusted so that the calculated emission of a specific HFC agrees with the emission derived from the observed atmospheric mixing ratios, using fixed emissions factors. Projections through 2050 (and 2100) are based on assumptions for growth in demand for HFCs and HCFCs (see below), the phaseout of HCFCs following the provisions of the Montreal Protocol and assumptions on how much this demand is met by HFCs or not-in-kind alternatives. The

195 procedure is similar to that of Velders et al. (2015). The baseline scenario of Velders et al. (2015) assumed unabated growth in HFC use and emissions. Since 2015, regulations to limit the use of HFCs are in place in the EU (EU, 2006, 2014), the USA (US-EPA, 2020), and Japan (METI, 2015) and reductions in HFC consumption are observed in several sectors (see Sect. 3). Therefore, the scenario presented here takes into account the reductions in HFC use from these regional and national regulations and is referred to as the "current policy" scenario. This scenario includes legislation adopted by parliaments in countries and implemented in national regulations as of the end of 2020 and does not include the provisions of the Kigali Amendment.

The demand for HCFCs and HFCs in developed countries in the various applications is

205 assumed to be saturated in 2018 and the demand after 2018 therefore changes proportional to the projected growth or decline in population in each of these five countries or world regions (see Sect. 2.2). This could underestimate the projected demand for HFCs considering, for example, the recent push in the EU for heat pumps to replace oil and gas for space heating. The demand in developing countries is assumed to be the sum of the demand for applications

210 that already use HFCs and the demand for applications in which HCFCs are currently or soon-to-be phased out and replaced in part by HFCs; it is assumed to change proportional to the growth or decline in Gross Domestic Product (GDP) for each of the six countries or world regions (see Sect. 2.2). The HCFC consumption from 1989 to 2019 reported to UNEP (2021) is the starting point for determining HCFC demand. The GDP and population data is taken

215 from the Shared Socioeconomic Pathway (SSP) projections (O'Neill et al., 2012). The "current policy" scenario consists of an upper range scenario following the GDP and population in the SSP5 pathway and a lower range scenario following the SSP3 pathway. 
In the "current policy" scenario, similar as in the 2015 baseline scenario, market saturation is assumed in developing countries when the demand reaches a level such that the sum of HFC and HCFC consumption per capita in that country or region reaches a level of the maximum consumption per capita of the developed countries. This saturation level is reached in different years for the different groups of sectors (domestic refrigeration, industrial and commercial refrigeration, stationary AC, mobile AC, foams, and other sectors). After saturation the consumption in each sector changes proportionally to population projections in a region.

The "current policy" scenario includes the policies in place to limit the use of HFCs, such as the EU mobile air conditioning directive (EU, 2006), the EU revised f-gas directive (EU, 2014), the American Innovation and Manufacturing act (US-EPA, 2020), and regulations in Japan (METI, 2015). This scenario also includes a phaseout of HFC-134a used for mobile air conditioning following recent trends in several countries. In the EU the use of fluorinated gases with a GWP greater than 150 has been prohibited for new vehicles since 2017 . Currently, the vast majority of new vehicles sold in the EU, the USA, and Japan are not equipped with HFC-134a, but with the low-GWP alternative hydrofluoroolefin HFO-1234yf (Taddonio, 2021). HFC-134a may still be used for recharging the AC systems in existing 235 vehicles. In the "current policy" scenario the consumption of HFC-134a for mobile AC is therefore reduced linearly from 2018 to 2030 in the EU, USA, Japan, and other OECD countries. The amount of HFC consumption in excess of the limits of the current policies is assumed to be replaced by low-GWP alternative substances of alternative technologies. In Sect. 3.2 we will show that the global emissions of HFC-143a inferred from observed mixing ratios is much lower than previously projected (Velders et al., 2015) and more or less constant from 2016 to 2019. This shows that the consumption of R-404A (the blend in which HFC-143a is mainly used in) for industrial and commercial refrigeration has been lower in recent years than previously projected. Therefore, for the upper range of the "current policy" scenario the consumption of HFCs for industrial and commercial refrigeration is constant at

245 the 2018 level for all developing countries. For the lower range of the "current policy" scenario, future consumption for these applications is still proportional to the growth in GDP in developing countries, allowing for the transition and use of other HFCs in this application. Following the provisions of the Montreal Protocol (UNEP, 2020), the consumption of HCFCs in developing countries is reduced stepwise with a full phaseout in 2040. In the baseline scenario the demand for HCFCs is then replaced by HFCs and not-in-kind replacements. We 
use here the same replacement schedule as by Velders et al. (2009) and Velders et al. (2015):

HCFC-22 is replaced by R-410A and R-404A (90\%) and low-GWP or not-in-kind alternatives (10\%); HCFC-141b and HCFC-142b are replaced by HFC-245fa and HFC$365 \mathrm{mfc}(50 \%)$ and by low-GWP alternatives (50\%).

\subsection{Kigali Amendment scenario}

The HFC phasedown schedule of the 2016 Kigali Amendment is applied to the consumption in the "current policy" scenario for a Kigali scenario assuming adoption by all countries of the world. The phasedown is applied to the total $\mathrm{CO}_{2}$-equivalent $\left(\mathrm{CO}_{2}\right.$-eq) $\mathrm{HFC}$ consumption using 100-yr GWPs to scale down the consumption in all sectors of a country or region by the same factor. The amount of HFC consumption in the "current policy" scenario in excess of the limits of the Kigali Amendment is assumed to be replaced by low-GWP alternative substances or alternative technologies.

\subsection{Box model}

The historical and projected HFC consumption is used in a global 1-box model to calculate the amounts present in equipment (the bank), the emissions, mixing ratios, and radiative forcing for each of the 10 HFCs, 12 use sectors, and 11 regions from 1990 to 2050 (or 2100) (see Velders and Daniel (2014) and Velders et al. (2015)). The emissions are calculated as a fraction of the bank as estimated from the UNFCCC (2021) data, see Table S1 (Supplement). In the box model a fixed atmospheric lifetime is used. The atmospheric lifetimes, the global

270 warming potentials (100 year time horizon), and radiative efficiencies are from WMO (2018). The HFC observations from both the AGAGE and NOAA/GML networks are used in the comparison of the inferred emissions with the emissions of the 2015 baseline scenario (Sect. 3.1 and 3.2). As a starting point for the new scenarios, only the observations from the AGAGE network are used (Sect. 3.4 to 3.6).

275 In the model, 12 separate use sectors taken are considered, 1) industrial refrigeration, 2) commercial (open compressor, hermetically sealed compressor), 3) transport refrigeration, 4) domestic refrigeration, 5) stationary AC, (6) mobile AC, 7) extruded polystyrene foams (XPS), 8) polyurethane foams (PUR), 9) open cell foams, 10) aerosol products, 11) fire extinguishing systems, and 12) solvents. 
280 The contribution of the HFCs to the global average surface warming is calculated from the emissions and atmospheric mole fractions derived from 1990 to 2100 using the low complexity carbon cycle-climate model MAGICC6 (Meinshausen et al., 2011a). This model has been calibrated with output from complex coupled atmosphere-ocean general circulation models and applied in several simulations (Meinshausen et al., 2011b).

\section{Results}

\subsection{Emissions baseline scenario compared with recent trends}

The 2015 baseline scenario from Velders et al. (2015) was based on reported HFC data for developed countries up to 2011, reported HCFC consumption data up to 2013, and observed $\mathrm{HFC}$ mixing ratios up to 2013. The global total $\mathrm{CO}_{2}$-eq emissions from the 2015 baseline scenario are compared with emissions inferred from HFC observations from the AGAGE and NOAA/GML networks from 2010 to 2020 (Figure 1). The inferred emission global totals are below the baseline emissions by about $20 \%$ in the period 2017-2019.

The baseline emissions of the HFCs with the largest global use, i.e., HFC-32, HFC-125, HFC-134a, and HFC-143a, are compared, individually, with the emissions inferred from observed mixing ratios (Figure 2). A comparison of the emissions of the other HFCs are shown in Figure S1 and a comparison of the mixing ratios in Figure S2 (see Supplement). The baseline emission projections of HFC-134a are in good agreement with the inferred emissions. The inferred emissions of HFC-32 and HFC-125 are lower than the baseline emissions, by about $19 \%$ and $25 \%$, respectively, averaged over 2017-2019. The largest difference is seen for HFC-143a; the inferred emissions are about $40 \%$ lower than the baseline emissions for 2017-2019.

The global total inferred emission of HFC-143a slowly increased through 2016, but are more or less constant from 2016 to 2019 (Figure 2). HFC-143a is used mainly (for $90 \%$ or more in our scenario) in the blend R-404A (52\% HFC-143a, 44\% HFC-125, 4\% HFC-134a) for industrial and commercial refrigeration applications (UNFCCC, 2021;UNEP, 2019). In the 2015 baseline scenario it was assumed that the global consumption of R-404A would increase following the growing demand for refrigeration applications, mainly in developing countries, and the phaseout of HCFC-22 under the Montreal Protocol. The fact that the global emissions of HFC-143a are significantly below the 2015 baseline scenario and constant in recent years, shows that R-404A is used in smaller amounts than expected to replace HCFC- 
22 for refrigeration applications. Other alternatives are likely used in larger amounts in this sector than expected previously (Velders et al., 2015). In Europe R-404A has already been replaced by an HFC blend (R-452A) without HFC-143a for new trucks (transport refrigeration), while propane and $\mathrm{CO}_{2}$ are also being used in commercial refrigeration 315 applications (UNEP, 2019).

\subsection{HFC-143a consumption trends}

Until about 2013, the majority (more than 80\%) of the HFC-143a emissions came from use in developed countries in the 2015 baseline scenario, estimated from the reported consumption data. In that scenario the consumption in developing countries increased by about a factor of 3203.5 from 2013 to 2019 , while that in developed countries increased by only $27 \%$ in the same period. Consequently, the 2015 scenario anticipated that 2019 emissions of HFC-143a would originate from developed and developing countries in equal amounts.

The EU and USA have the largest reported use (consumption) of HFC-143a of all developed (Annex 1) countries (UNFCCC, 2021). The use in the EU has decreased by about $60 \%$ in

3252017 compared to 2010. This decrease is ahead of the ban for HFCs with a GWP larger of 2500 or more for commercial refrigeration applications, in effect since 2020 (EU, 2014). In the USA the use of HFC-143a increased by $14 \%$ in 2017 compared to 2010, while small increases are also seen in other developed countries. In sum, the total Annex 1 use (consumption) decreased by about $8 \%$ in 2017 compared to 2010 (Figure 3).

330 The largest growth in HFC-143a in the baseline scenario was projected for China, with an increase of a factor of six from 2010 to 2017 (Velders et al., 2015). This projected increase was based on the cap and initial phaseout of HCFC-22 and large projected economic growth in China. According to Li et al. (2019) the consumption of HFC-143a in China also increased by a factor of six from 2010 to 2017, but the absolute values are much lower than in the

335 scenario. The consumption for China in the baseline scenario was based on Zhang and Wang (2014) and Fang et al. (2016) and is about ten times larger than that reported by Li et al. (2019) for 2005-2013; a 2013 consumption is $0.8 \mathrm{kt}$ in Li et al. (2019) versus 6.4 kt in Fang et al. (2016). The lower reported consumption of HFC-143a from Li et al. (2019) takes into account export of HFCs. Information on export of HFCs, which is significant for HFC-143a,

340 was not available for the studies from Zhang and Wang (2014) and Fang et al. (2016) (personal communication Jianxin $\mathrm{Hu}$ ). 
Based on the decreased use of HFC-143a in the EU, limited increases in other developed countries, and lower reported consumption in China, the " 2015 baseline" was adjusted to test if the observed trend in emissions can be matched with a simple adjustment. In this "Reduced

345 HFC production ICR" scenario the use of HFCs for industrial and commercial refrigeration (ICR) in developed countries was reduced following the UNFCCC reported reduction in HFC-143a from 2013 to 2020, while the use in developing countries was held constant at the 2013 level. With these adjustments to the baseline scenario in the "Reduced HFC production ICR" scenario, emissions of HFC-143a and also of HFC-125 (also part of the blend R-404A) 350 are close to the emissions inferred from observations (Figure 2). With this single adjustment the $\mathrm{CO}_{2}$-eq emissions of all HFCs closely follow the emissions inferred from observations (Figure 1). This adjustment was directly included in the "current policy" scenario since it is based on the historical UNFCCC reported data.

\subsection{Reported HCFC and HFC consumption}

355 The total reported HCFC consumption in both developed and developing countries is decreasing (Figure 3). In 2019, the consumption in developed countries was about $98 \%$ below the 1990s peak, while the consumption in developing countries was about $60 \%$ lower than the peak in 2012. The reported HCFC phaseout in developed countries is already virtually complete in line with the assumption in the "current policy" scenario discussed here

360 (Sect. 2.3). For both groups of countries, the total HCFC consumption was below the limits set by the Montreal Protocol for all years. This potentially provided additional pressure on demand for HFCs to replace HCFCs and compounding the demand associated with the required HCFC phaseout schedule.

The global HFC consumption derived here from the reported UNFCCC (2021) activity data

365 and emissions shows strong increases for HFC-32 and HFC-125 (Figure 3), prior to scaling to match observation derived emissions, albeit less than projected in the 2015 baseline scenario. Both compounds are predominantly used in the blend R-410A in stationary AC (about $90 \%$ of HFC-32 and 63\% of HFC-125 in 2017), leading to the conclusion that the use of HFCs in stationary ACs is increasing strongly in developed countries.

370 The consumption of HFC-134a increased in developed countries until about 2010 after which it started to decrease (Figure 3). This HFC is used in many applications of which mobile AC is the largest; about $43 \%$ of all HFC-134a consumption in developed countries was in this sector in 2017. The decrease since 2010 is mainly from less use in mobile AC in the EU and 
USA. The consumption for mobile AC in the EU and USA stabilized between 2000 and 2010 and then decreased, probably as a result of smaller charges and less frequent recharging of existing systems (as a result of reduced leakage rates). Adding to this slowdown was the introduction of HFO-1234yf for mobile AC around 2012 (Vollmer et al., 2015), reducing the use of HFC-134a for this applications further in the EU and USA.

The trend in consumption of HFC-143a is discussed in Sect. 3.2.

\subsection{Current policy scenario}

The $\mathrm{CO}_{2}$-eq emissions and radiative forcing of the "current policy" scenario are compared with the 2015 baseline scenario for the period up to 2050 (Figure 4). The difference in scenarios from 2010 to 2020 arises from the difference between the projections of the 2015 scenario and the inferred observations included in the "current policy" scenario. Both scenarios use the emissions inferred from observed mixing ratios as a starting point. For the 2015 baseline scenario, observational-based emissions were available up to 2012 and for the "current policy" scenario they were available through the year 2019. The 2050 emissions in "current policy" scenario are 1.6-2.1 $\mathrm{GtCO}_{2}$-eq $\mathrm{yr}^{-1}$ lower than in the baseline scenario (1.93.6 versus 4.0-5.3 $\left.\mathrm{GtCO}_{2}-\mathrm{eq} \mathrm{yr}^{-1}\right)$. This difference comes from the different assumptions in

390 the projections, mainly the lower projected consumption of HFC-125 and HFC-143a for industrial and commercial refrigeration in developed and developing countries (see Sect. 3.2). Smaller contributions come from the transition from HFC-134a to HFO-1234yf in mobile AC in developed countries, and the implementation of other provisions of the current regional and national HFC regulations in the EU, the USA, and Japan (see Sect. 2.3).

395 The effect of the regulations in the EU, the USA, and Japan, including the changes in mobile $\mathrm{AC}$, are estimated to reduce the global emissions by $0.4-0.5 \mathrm{GtCO}_{2}$-eq $\mathrm{yr}^{-1}$ in 2050 , relative to the "current policy" scenario (not shown).

The effects of the regulations are also evident in the emissions projections of HFC-32, -125, 134a, and -143a in Figure 5. See Figure S3 for the other HFCs in the Supplement. The lower emissions in HFC-125 and HFC-143a in the "current policy" scenario compared to the 2015 baseline scenario (Figure 5) contribute most to the difference in $\mathrm{CO}_{2}$-eq emissions (Figure 4) due to the large GWPs of 3450 and 5080 (WMO, 2018), respectively. These differences in emissions translate into a difference in 2050 radiative forcing of $0.08-0.09 \mathrm{~W} \mathrm{~m}^{-2}(0.13-0.18$ $\mathrm{W} \mathrm{m}^{-2}$ in the "current policy" scenario versus $0.22-0.25 \mathrm{~W} \mathrm{~m}^{-2}$ in the baseline scenario). 
405 The contributions of the different world regions and application sectors to the $\mathrm{CO}_{2}$-eq emissions and radiative forcing of the upper range of the "current policy" scenario are shown in Figure 6. While the contributions to the emissions and radiative forcing in developed countries decrease after about 2020 and 2040, respectively, the contributions from developing countries continue to grow in the absence of the provisions of the Kigali Amendment. The

410 largest contributions are from China (34\% in $\mathrm{CO}_{2}$-eq emissions and $40 \%$ in radiative forcing for the upper range of the "current policy" scenario for 2050), followed by India (19\% and $13 \%$, respectively). Considering the use sectors, the largest contributions for the upper range of the "current policy" scenario are from ICR and stationary AC applications with $41 \%$ and $37 \%$, respectively of the total in 2050 . For the lower range of the "current policy" scenario

415 the contributions from ICR applications are strongly reduced and stationary AC applications have the largest contributions to both emissions and radiative forcing, with $56 \%$ and $47 \%$, respectively, in 2050 (not shown).

\subsection{Kigali Amendment scenario}

The provisions of the 2016 Kigali Amendment are projected to reduce the 2050 HFC emissions from 1.9-3.6 $\mathrm{GtCO}_{2}$-eq $\mathrm{yr}^{-1}$ in the "current policy" scenario to $0.9-1.0 \mathrm{GtCO}_{2}$ eq $\mathrm{yr}^{-1}$ (Figure 4). This is slightly lower than projected relative to the 2015 baseline scenario, because of a lower Kigali baseline levels (average consumption of 2020-2022 or 2024-2026) for developing countries. The corresponding radiative forcing in the "current policy" scenario is reduced from $0.13-0.18 \mathrm{~W} \mathrm{~m}^{-2}$ to $0.09-0.10 \mathrm{~W} \mathrm{~m}^{-2}$ in 2050 by the provisions of the Kigali 425 Amendment.

\subsection{Zero production and emissions scenario}

In two hypothetical scenarios that incorporate a cessation in global production or emissions of HFCs in 2023, the emissions and radiative forcing is further reduced (Figure 4). With a cessation in production in 2023 the radiative forcing drops to about $0.03 \mathrm{~W} \mathrm{~m}^{-2}$ by 2050 ,

430 while if all emissions (from new production and from banks) cease in 2023 it is reduced to about $0.01 \mathrm{~W} \mathrm{~m}^{-2}$ by 2050 , compared to $0.09-0.10 \mathrm{~W} \mathrm{~m}^{-2}$ considering the provisions of the Kigali Amendment. 


\subsection{Surface temperature contributions by HFCs}

Radiative forcing of greenhouse gases contributes to global surface warming, changes in atmospheric circulation, and other effects. The contribution of emissions and radiative forcing of HFCs (Figure 4) to the surface warming is calculated using the MAGICC6 model (Meinshausen et al., 2011a) and shown in Figure 7. For this calculation the scenarios are extended to 2100 based on the same assumptions as used for the period 2020-2050. In the "current policy" scenario the HFCs are projected to contribute $0.14-0.31^{\circ} \mathrm{C}$ to the global

440 average surface warming in 2100 , compared to $0.28-0.44{ }^{\circ} \mathrm{C}$ in the 2015 baseline scenario (Velders et al., 2015;Montzka and Velders et al., 2018). With the provisions of the Kigali Amendment the surface warming of the HFCs drops to about $0.04{ }^{\circ} \mathrm{C}$ in 2100 . For comparison, all greenhouse gases are projected to contribute $1.4-4.8^{\circ} \mathrm{C}$ to the surface warming by the end of the $21^{\text {st }}$ century following the RCP6 and RCP8.5 scenarios (IPCC,

445 2013). In hypothetical scenarios with a cessation in global production or emissions of HFCs in 2023 the contribution to the surface warming is reduced to virtually zero $\left(0.01{ }^{\circ} \mathrm{C}\right.$ and $0.004{ }^{\circ} \mathrm{C}$ in 2100 , respectively).

\section{Discussion and conclusions}

We analyzed trends in observations of atmospheric abundances of ten different HFCs from 1990 to 2020 and the emissions inferred from these observations and compared them with previous projections. Total $\mathrm{CO}_{2}$-eq $\mathrm{HFC}$ emissions inferred from observations continue to increase through 2019, but are about 20\% lower than previously projected for 2017-2019. The main reason is lower global inferred emissions of HFC-143a during 2012-2019. This HFC is mainly used in the blend R-404A in ICR applications. Data reported to the UNFCCC also show lower than projected consumption of HFC-143a with a reduction in use in the EU and a stabilization in the USA and Japan. Consumption data reported for China also shows a reduced use of HFC-143a (Li et al., 2019). These lower emissions and reduced consumption cannot be linked directly to the provisions of the Kigali Amendment, since that only came into force in January 2019. It could indicate that companies transitioned away from higher GWP HFCs, HFC-143a in particular, for ICR applications prior to national or global regulation mandates. For example, in the EU, the use of any HFC with a GWP of 2500 or more, such as HFC-143a (GWP 5080), is banned from use in ICR applications since January 2020, but companies appear to have switched to lower-GWP or not-in-kind alternatives 
before this date. This could also explain the observed emissions reduction of HFC-125 which is used together with HFC-143a in R-404A.

The HFC emissions reported by Annex 1 (developed) countries to the UNFCCC are roughly constant throughout the period 2014-2018 and account for about half of global total emissions inferred from observations during these years. This gap is predominantly not the result of underreporting by Annex 1 countries (at least not from the EU and the US, for which atmospheric measurement based emissions estimates are in general agreement with UNFCCC reporting), but instead is associated with substantial emissions from non-Annex 1 countries (Montzka and Velders et al., 2018).

New HFC scenario projections are developed based on the trends in the use of HFCs in developed and developing countries, current policies in effect in the EU, the USA and Japan, and emissions inferred from observed abundances as constraints until 2019. In this "current policy" scenario, the $2050 \mathrm{HFC}$ emissions of 1.9-3.6 $\mathrm{GtCO}_{2}$-eq $\mathrm{yr}^{-1}$ are substantially lower than in a baseline scenario derived without any control measures or anticipation of control measures of 4.0-5.3 $\mathrm{GtCO}_{2}$-eq $\mathrm{yr}^{-1}$. The provisions of the Kigali Amendment in addition to the current policies are projected to reduce the emissions further to $0.9-1.0 \mathrm{GtCO}_{2}$-eq $\mathrm{yr}^{-1}$ in 4802050 , which is very similar to total HFC emissions in 2019 of about $0.8 \mathrm{GtCO}_{2}$-eq yr${ }^{-1}$. Global emissions of all fluorinated gases have recently been estimated by Purohit et al. (2020) using projections of activity data in various sectors and taking into account national and regional emission controls in place as of 2016 when the Kigali Amendment was adopted. Their baseline 2050 emissions are about $4.3 \mathrm{GtCO}_{2}$-eq yr ${ }^{-1}$, which is consistent with our 2015 baseline, but higher than our "current policy" scenario that includes the consideration of additional control measures in some countries.

Li et al. (2019) reported projections of HFC use and emissions for China. Their 2050 business-as-usual $\mathrm{HFC}$ emissions are about $0.9 \mathrm{GtCO}_{2}$-eq $\mathrm{yr}^{-1}$, which agrees well with our "current policy" (e.g., not including the Kigali Amendment) estimate for China of 0.9-1.3

$490 \mathrm{GtCO}_{2}$-eq $\mathrm{yr}^{-1}$. In our scenario we use the Chinese historical HFC consumption from 1995 to 2017 from Li et al. (2019) as a starting point, but with somewhat different assumptions with respect to growth rates and market saturation. Li et al. (2019) estimated total Chinese HFCs emissions in 2050, considering compliance with the Kigali Amendment, of about 0.20 $\mathrm{GtCO}_{2}$-eq $\mathrm{yr}^{-1}$ which is slightly lower than our estimate of about $0.43 \mathrm{GtCO}_{2}$-eq $\mathrm{yr}^{-1}$. Liu et al. (2019) reported projections specifically for room AC in China and estimated 2050 
emissions of $0.13-0.26 \mathrm{GtCO}_{2}$-eq $\mathrm{yr}^{-1}$ for this use sector. This number cannot be directly compared with our scenario since we have one sector of stationary AC, which consists of both residential and commercial AC.

Projected mixing ratios, radiative forcing, and globally averaged temperature changes are calculated from the projected HFC emissions. The 2050 radiative forcing is $0.13-0.18 \mathrm{~W} \mathrm{~m}^{-2}$ in the "current policies" scenario and drops to $0.08-0.09 \mathrm{~W} \mathrm{~m}^{-2}$ when the additional Kigali Amendment controls are considered. In the current policies scenario, the HFCs are projected to contribute $0.14-0.31^{\circ} \mathrm{C}$ to the global surface warming in 2100 , compared to $0.28-0.44^{\circ} \mathrm{C}$ without policies. Following the Kigali Amendment, the surface warming of HFCs is reduced to about $0.05{ }^{\circ} \mathrm{C}$ in 2050 and $0.04^{\circ} \mathrm{C}$ in 2100 . In a hypothetical scenario with a full phaseout of HFCs production and consumption in 2023 the contribution is reduced to about $0.01{ }^{\circ} \mathrm{C}$ in 2100.

Projected $\mathrm{CO}_{2}$-eq emissions, radiative forcing, and climate warming calculated here are only from the direct effects of projected emissions of HFCs. There are also indirect emissions of

510 greenhouse gases associated with the production and use of HFCs in various applications. For example, AC systems use electricity to operate and, depending on the manner in which the electricity is generated, significant emissions of $\mathrm{CO}_{2}$ can occur. This and other indirect effects arising from the use of HFCs and/or alternative substances and technologies need to be considered to estimate the complete effect of HFCs and alternatives and the Kigali

515 Amendment on climate. For example, switching to superefficient low-GWP alternatives in room AC systems and cooling equipment in general has both direct and indirect climate benefits (Shah et al., 2015, 2019). Purohit et al. (2020) estimated significant electricity savings from a global phasedown of HFCs in addition to the saving in GWP-weighted emissions from HFCs directly.

520 In conclusion, the current observed trends in developed and developing countries and policies in several developed countries reduce the projected global average surface warming attributed to HFC emissions (excluding HFC-23) by about $0.14{ }^{\circ} \mathrm{C}$ (from $0.28-0.44$ to 0.14 $0.31{ }^{\circ} \mathrm{C}$ ) in 2100 compared to earlier estimates that didn't include the updated data and new controls. A further reduction of $0.10-0.26{ }^{\circ} \mathrm{C}$ (to about $0.04{ }^{\circ} \mathrm{C}$ ) is possible in 2100 with the 525 global implementation and compliance with the provisions of the Kigali Amendment. 
Acknowledgements. We thank Jianxin Hu (University of Beijing) for information about use of HFC in China and Kristen Taddonio (Institute for Governance \& Sustainable Development) for information of HFC use for mobile AC. The five AGAGE stations from

530 which ambient measurements were used here are supported by the National Aeronautics and Space Administration (NASA) (grants NNX16AC98G to MIT, NNX16AC97G and NNX16AC96G to SIO, and preceding grants). Support also comes from the UK Department for Business, Energy \& Industrial Strategy (BEIS, contract 1537/06/2018 to the University of Bristol) for Mace Head, the National Oceanic and Atmospheric Administration (NOAA, contract 1305M319CNRMJ0028 to the University of Bristol) for Ragged Point, and the Commonwealth Scientific and Industrial Research Organization (CSIRO) and the Bureau of Meteorology (Australia) for Cape Grim. NOAA measurements of HFCs benefited from the technical assistance of C. Siso, B. Hall, B. Miller, M. Crotwell, personnel at remote sampling stations, and funding in part from the NOAA Climate Program Office's AC4 program.

Author contributions. GJMV designed the research, collected and analyzed the consumption data, and performed the calculations. JSD, SAM and MR assisted with the research design. Measurement data were collected by SAM, IV, MR, PBK, JM, SOD, RGP, RFW, and DY. GJMV wrote the article, with contributions from all co-authors. 


\section{References}

EU: Directive 2006/40/EC of the European parliament and of the council of 17 May 2006 relating to emissions from air-conditioning systems in motor vehicles, Official J. EU, L161, 12-18, 2006.

550 EU: Regulation (EC) No 517/2014 of the European parliament and of the council of 16 April 2014 on fluorinated greenhouse gases and repealing Regulation (EC) No 842/2006, Official J. EU, L 150, 195-230, 2014.

Fang, X., Velders, G. J. M., Ravishankara, A. R., Molina, M. J., Hu, J., and Prinn, R. G.: Hydrofluorocarbon (HFC) emissions in China: An inventory for 2005-2013 and projections

555 to 2050, Environ. Sci. Technol., 50, 2027-2034, https://doi.org/10.1021/acs.est.5b04376, 2016.

Flerlage, H., Velders, G. J. M., and de Boer, J.: A review of bottom-up and top-down emission estimates of hydrofluorocarbons (HFCs) in different parts of the world, Chemosphere, 283, 131208, https://doi.org/10.1016/j.chemosphere.2021.131208, 2021.

560 Gschrey, B., Schwarz, W., Elsner, C., and Engelhardt, R.: High increase of global F-gas emissions until 2050, Greenhouse Gas Measurement \& Management, 1, 85-92, https://doi.org/10.1080/20430779.2011.579352, 2011.

Hu, L., Montzka, S. A., Miller, J. B., Andrews, A. E., Lehmann, S. J., Miller, B. R., Thoning, K., Sweeney, C., Chen, H., Godwin, D. S., Masarie, K., Bruhwiler, L., Fischer, M. L., Biraud,

565 S. C., Torn, M. S., Mountain, M., Nehrkorn, T., Eluszkiewicz, J., Miller, S., Draxler, R. R., Stein, A. F., Hall, B. D., Elkins, J. W., and Tans, P. P.: U.S. emissions of HFC-134a derived for 2008-2012 from an extensive flask-air sampling network, J. Geophys. Res., 120, 801825, https://doi.org/10.1002/2014JD022617, 2015.

Hu, L., Montzka, S. A., Lehman, S. J., Godwin, D. S., Miller, B. R., Andrews, A. E.,

570 Thoning, K., Miller, J. B., Sweeney, C., Siso, C., Elkins, J. W., Hall, B. D., Mondeel, D. J., Nance, D., Nehrkorn, T., Mountain, M., Fischer, M. L., Biraud, S. C., Chen, H., and Tans, P. P.: Considerable contribution of the Montreal Protocol to declining greenhouse gas emissions from the United States, Geophys. Res. Lett., 44, 8075-8083, https://doi.org/10.1002/2017GL074388, 2017.

575 IPCC: Climate Change 2013: The physical science basis, edited by: Stocker, T. F., and Qin, D., Cambridge Univ Press, Cambridge, UK and New York, 2013.

Li, Y.-X., Zhang, Z.-Y., An, M.-D., Gao, D., and Hu, J.-X.: The estimated schedule and mitigation potential for hydrofluorocarbons phase-down in China, Advances in Climate Change Research, 10, 174-180, https://doi.org/10.1016/j.accre.2019.10.002, 2019.

580 Liu, L., Dou, Y., Yao, B., Bie, P., Wang, L., Peng, M., and Hu, J.: Historical and projected HFC-410A emission from room air conditioning sector in China, Atmos. Environ., 212, 194200, https://doi.org/10.1016/j.atmosenv.2019.05.022, 2019.

Manning, A., Redington, A. L., Say, D., O'Doherty, S., Young, D., Simmonds, P. G., Vollmer, M. K., Muhle, J., Arduini, J., Spain, G., Wisher, A. M., M., Schuck, T. J., Stanley,

585 K., Reimann, S., Engel, A., Krummel, P. B., Fraser, P., Harth, C., Salameh, P. K., Weiss, R. F., Gluckman, R., Brown, P. N., Watterson, J. D., and Arnold, T.: Evidence of a recent decline in UK emissions of HFCs determined by the InTEM inverse model and atmospheric measurements, Atmos. Chem. Phys., 21, 12739-12755, https://doi.org/10.5194/acp-2112739-2021, 2021. 
590 Meinshausen, M., Raper, S. C. B., and Wigley, T. M. L.: Emulating coupled atmosphereocean and carbon cycle models with a simpler model, MAGICC6 - Part 1: Model description and calibration, Atmos. Chem. Phys., 11, 1417-1456, https://doi.org/10.5194/acp-11-14172011, 2011a.

Meinshausen, M., Wigley, T. M. L., and Raper, S. C. B.: Emulating coupled atmosphereocean and carbon cycle models with a simpler model, MAGICC6 - Part 2: Applications, Atmos. Chem. Phys., 11, 1457-1471, https://doi.org/10.5194/acp-11-1457-2011, 2011 b.

METI: Act on the rational use and proper management of fluorocarbons (Act no. 64 of 2001), http://conf.montreal-

protocol.org/meeting/workshops/hfc_management/presentations/Statements by Heads of Delegations/4-Masafumi Ohki_session_4.ppt, Ministry of Economy, Trade and Industry, Japan, Tokyo, 2015.

Montzka, S. A., McFarland, M., Andersen, S. O., Miller, B. R., Fahey, D. W., Hall, B. D., $\mathrm{Hu}, \mathrm{L}$., Siso, C., and W., E. J.: Recent trends in global emissions of hydrochlorofluorocarbons and hydrofluorocarbons - Reflecting on the 2007 Adjustments to the Montreal Protocol,

605 Journal of Physical Chemistry A, 119, 4439-4449, https://doi.org/10.1021/jp5097376, 2015.

Montzka, S. A., Velders, G. J. M. (lead authors), Krummel, P. B., Mühle, J., Orkin, V. L., Park, S., Shah, N., and Walter-Terrinoni, H.: Hydrofluorocarbons (HFCs), in: Chapter 2 in Scientific Assessment of Ozone Depletion: 2018, Global Ozone Research and Monitoring, World Meteorological Organization, Geneva, Switzerland, 2018.

610 NIES: National greenhouse gas inventory report of Japan, edited by: Studies, N. I. o. E., Center for Global Environmental Research, National Institute for Environmental Studies, National Institute of Environmental Studies., Tsubuka, Japan, 2020.

O'Neill, B. C., Carter, T. R., Ebi, K. L., Edmonds, J., Hallegatte, S., Kemp-Benedict, E., Kriegler, E., Mearns, L., Moss, R., Riahi, K., van Ruijven, B., and van Vuuren, D.: Meeting

615 Report of the Workshop on The Nature and Use of New Socioeconomic Pathways for Climate Change Research, Boulder, CO, November 2-4, 2011,(database version 0.93), https://secure.iiasa.ac.at/web-apps/ene/SspDb/dsd?Action=htmlpage\&page=about International Institute for Applied System Analysis, Laxenburg, AustriaUNEP/OzL.Pro.16/4, 110, 2012.

620 Prinn, R. G., Weiss, R. F., Arduini, J., Arnold, T., DeWitt, H. L., Fraser, P. J., Ganesan, A. L., Gasore, J., Harth, C. M., Hermansen, O., Kim, J., Krummel, P. B., Li, S., Loh, Z. M., Lunder, C. R., Maione, M., Manning, A. J., Miller, B. R., Mitrevski, B., Mühle, J., O’Doherty, S., Park, S., Reimann, S., Rigby, M., Saito, T., Salameh, P. K., Schmidt, R., Simmonds, P. G., Steele, L. P., Vollmer, M. K., Wang, R. H., Yao, B., Yokouchi, Y., Young, 625 D., and Zhou, L.: History of chemically and radiatively important atmospheric gases from the Advanced Global Atmospheric Gases Experiment (AGAGE), Earth System Science Data, 10, 985-1018, http://agage.mit.edu/, https://doi.org/10.5194/essd-10-985-2018, 2018.

Purohit, P., and Hoglund-Isaksen, L.: Global emissions of fluorinated greenhouse gases 2005-2050 with abatement potentials and costs, Atmos. Chem. Phys., 17, 2795-2816,

630 https://doi.org/10.5194/acp-17-2795-2017, 2017.

Purohit, P., Hoglund-Isaksen, L., Dulac, J., Shah, N., Wei, M., Rafaj, P., and Schopp, W.: Electricity savings and greenhouse gas emission reductions from global phase-down of hydrofluorocarbons, Atmos. Chem. Phys., 20, 11305-11327, https://doi.org/10.5194/acp-2011305-2020, 2020. 
635 Say, D., Ganesan, A. L., Lunt, M. F., Rigby, M., O'Doherty, S., Harth, C., Manning, A. J., Krummel, P. B., and Bauguitte, S.: Emissions of halocarbons from India inferred through atmospheric measurements, Atmos. Chem. Phys., 19, 9865-9885, https://doi.org/10.5194/acp19-9865-2019, 2019.

Shah, N., Wei, M., Letschert, V. E., and Phadke, A.: Benefits of leapfrogging to

640 superefficiency and low global warming potential refrigerants in room air conditioning, Lawrence Berkeley National Laboratory (LBNL), Berkeley, USALBLN-1003671, 2015.

Shah, N., Wei, M., Letschert, V. E., and Phadke, A.: Benefits of energy efficient and lowglobal warming potential refrigerant cooling equipment, Lawrence Berkeley National Laboratory (LBNL), Berkeley, USALBLN-2001229, 2019.

645 Stanley, K. M., Say, D., Muhle, J., Harth, C. M., Krummel, P. B., Young, D., O’Doherty, S. J., Salameh, P. K., Simmonds, P. G., Weiss, R. F., Prinn, R. G., Fraser, P. J., and Rigby, M.: Increase in global emissions of HFC-23 despite near-total expected reductions, Nature Communications, 11, 397, https://doi.org/10.1038/s41467-019-13899-4, 2020.

Taddonio, K.: Global number of vehicles using HFO-1234yf refrigerant, Institute for

650 Governance and Sustainable Development, Washington DC, USA, 2021.

UNEP: Technology and Economic Assessment Panel. 2018 Assessment report, United Nations Environment Programme, Nairobi, Kenya, 2019.

UNEP: Handbook for the Montreal Protocol on substances that deplete the ozone layer. http://ozone.unep.org/, Ozone Secretariat, United Nations Environment Programme (UNEP), 655 Nairobi, Kenya, 2020.

UNEP: Production and consumption of ozone depleting substances under the Montreal Protocol. http://ozone.unep.org (last access: April 2021), United Nations Environment Programme, Nairobi, Kenya, 2021.

UNFCCC: National Inventory Submissions 2020 to the United Nations Framework

660 Convention of Climate Change, http://unfccc.int (last access: Februari 2021 ), Climate Change Secretariat, Bonn, Germany, 2021.

US-EPA: American Innovation and Manufacturing (AIM) Act, US Environmental Protection Agency, Washington, 2020.

Velders, G. J. M., Fahey, D. W., Daniel, J. S., McFarland, M., and Andersen, S. O.: The large 665 contribution of projected HFC emissions to future climate forcing, Proc. Nat. Acad. Sci., 106, 10949-10954, https://doi.org/10.1073/pnas.0902817106, 2009.

Velders, G. J. M., and Daniel, J. S.: Uncertainty analysis of projections of ozone-depleting substances: Mixing ratios, EESC, ODPs, and GWPs, Atmos. Chem. Phys., 14, 2757-2776, https://doi.org/10.5194/acp-14-2757-2014, 2014.

670 Velders, G. J. M., Fahey, D. W., Daniel, J. S., Andersen, S. O., and McFarland, M.: Future atmospheric abundances and climate forcings from scenarios of global and regional hydrofluorocarbon (HFC) emissions, Atmos. Environ., 123, 200-209, https://doi.org/10.1016/j.atmosenv.2015.10.071, 2015.

Vollmer, M. K., Reimann, S., Hill, M., and Brunner, D.: First observations of the fourth

675 generation synthetic halocarbons HFC-1234yf, HFC-1234ze(E), and HCFC-1233zd(E) in the atmosphere, Environ. Sci. Technol., 49, 2703-2708, https://doi.org/10.1021/es505123x, 2015 . 
WMO: Scientific Assessment of Ozone Depletion: 2018, Global Ozone Research and Monitoring Project, No. 58, World Meteorological Organization, Geneva, 2018.

680 Xu, Y., Zaelke, D., Velders, G. J. M., and Ramanathan, V.: The role of HFCs in mitigating 21st century climate change, Atmos. Chem. Phys., 13, 6083-6089, https://doi.org/10.5194/acp-13-6083-2013, 2013.

Yao, B., Fang, X., Vollmer, M. K., Reimann, S., Chen, L., Fang, S., and Prinn, R. G.: China's hydrofluorocarbon emissions for 2011-2017 inferred from atmospheric measurements,

685 Environmental Science and Technology Letters, 6, 479-486, https://doi.org/10.1021/acs.estlett.9b00319, 2019.

Zhang, J., and Wang, C.: China's hydrofluorocarbons challenge, Nature Climate Change, 4 , 943-945, 2014. 


\section{Figures}

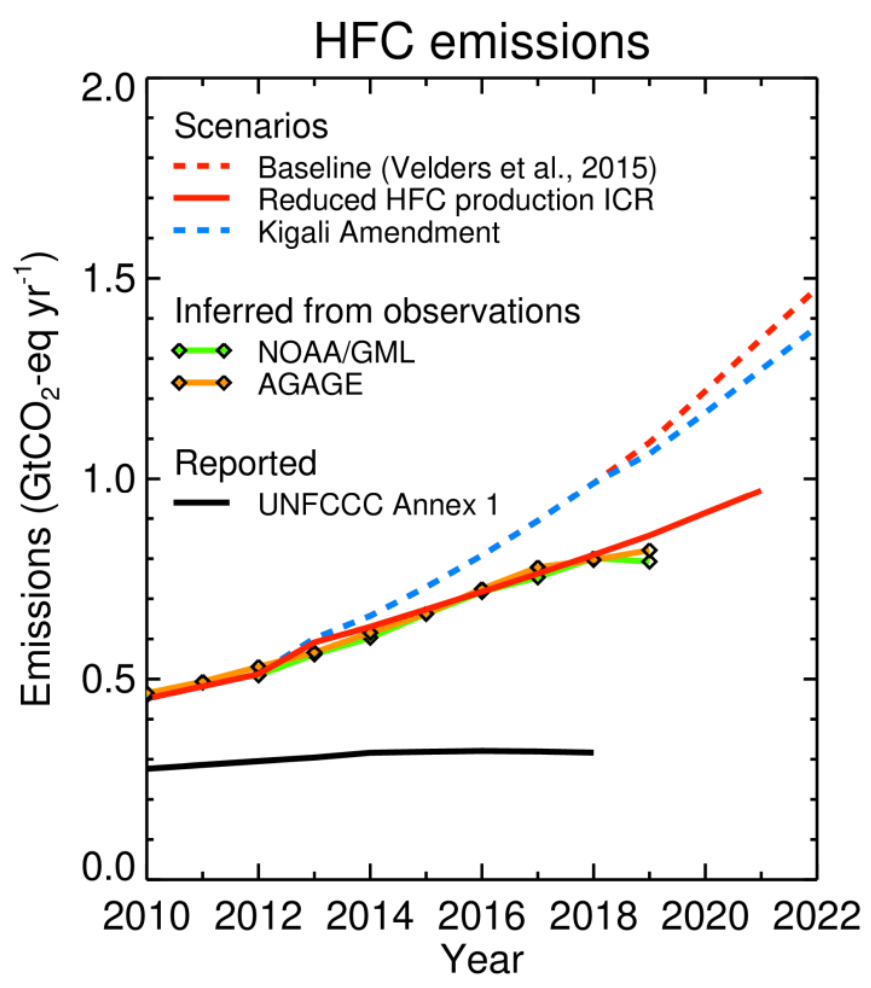

Figure 1: Global total HFC emissions $\left(\mathrm{GtCO}_{2}-\mathrm{eq}^{-1}{ }^{-1}\right)$ from the 2015 baseline scenario, the

6952016 Kigali Amendment scenario, and inferred from observed mixing ratios from the AGAGE and NOAA/GML networks (see methods). The solid line shows an adjusted scenario with reduced HFC consumption for industrial and commercial refrigeration (ICR) from 2013 onward. The curves contain the contributions from all HFC emissions, except HFC-23. The scenarios were constrained by the emissions inferred from observed mixing

700 ratios up to 2013. Also shown are the emissions reported to the UNFCCC by developed (Annex 1) countries. 

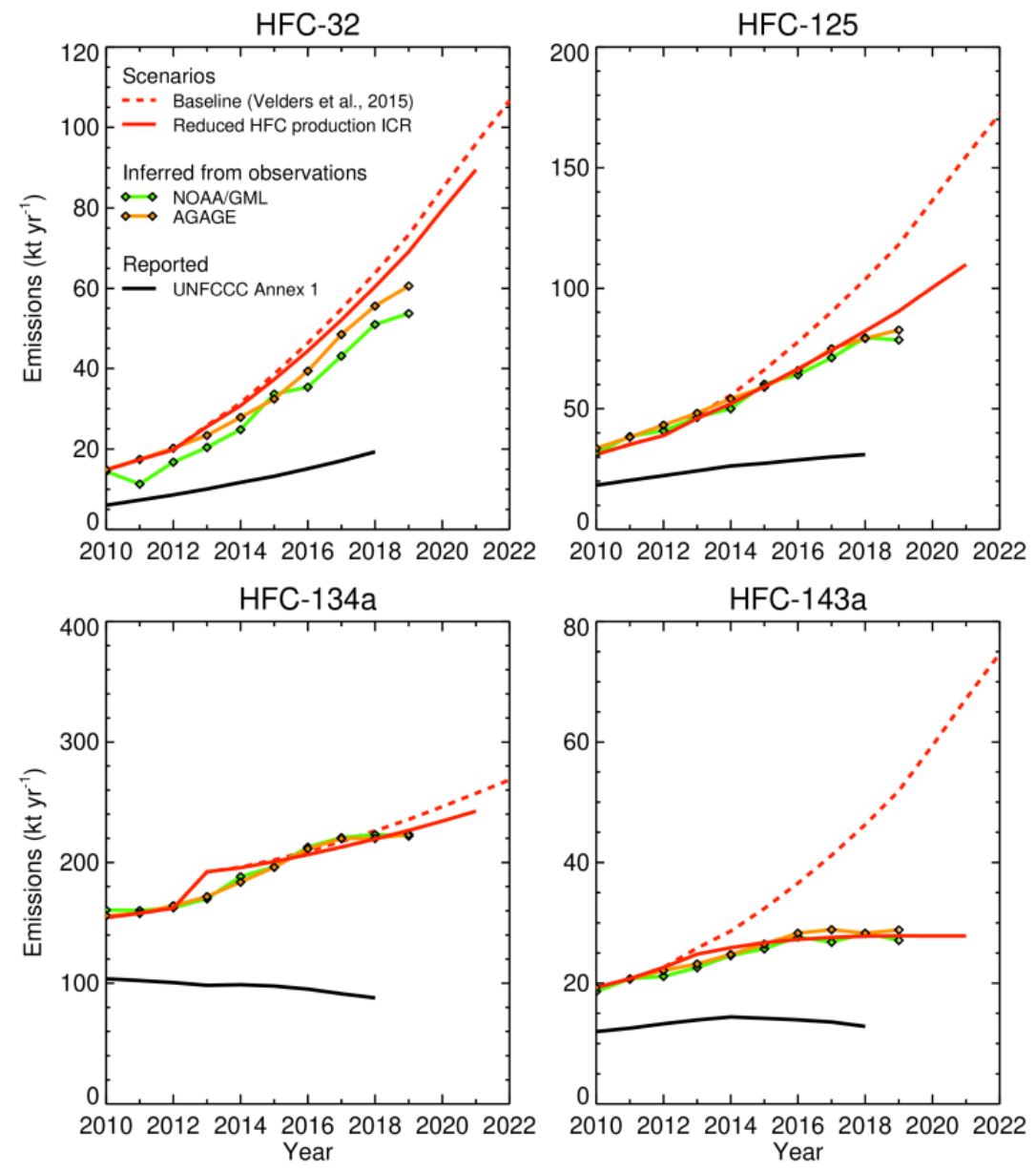

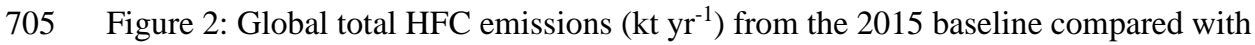
emissions inferred from observed mixing ratios from the AGAGE and NOAA/GML networks. The solid line shows an adjusted scenario with reduced HFC production for industrial and commercial refrigeration (ICR) from 2013 onward. Also shown are the emissions reported to the UNFCCC by Annex 1 countries. The scenarios were constrained by the emissions inferred from observed mixing ratios up to 2013. The AGAGE data is from the observations at Mace Head (Ireland), Trinidad Head (Barbados), Ragged Point (Barbados), Cape Matatula (American Samoa), Cape Grim (Tasmania). The NOAA data is from the stations at Alert (Canada), Barrow (Alaska), Niwot Ridge (Colorado), Mauna Loa (Hawaii), Kumukahi (Hawaii), American Samoa, Cape Grim (Tasmania), and South Pole. 

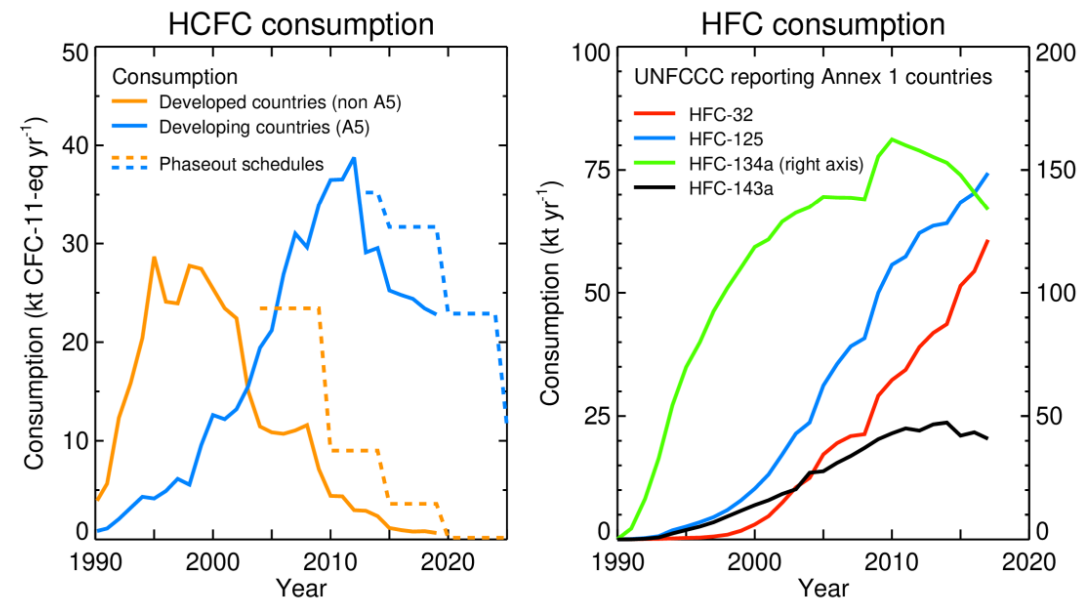

Figure 3: Left panel: HCFC consumption (kt CFC-11-eq $\mathrm{yr}^{-1}$ ) in developed (non A5) and developing (A5) countries as reported to UNEP (2021) and the Montreal Protocol phaseout schedules. Right panel: HFC consumption $\left(\mathrm{kt}^{-1}\right)$ in developed countries (Annex 1 countries) derived from the data reported to the UNFCCC (2021). 

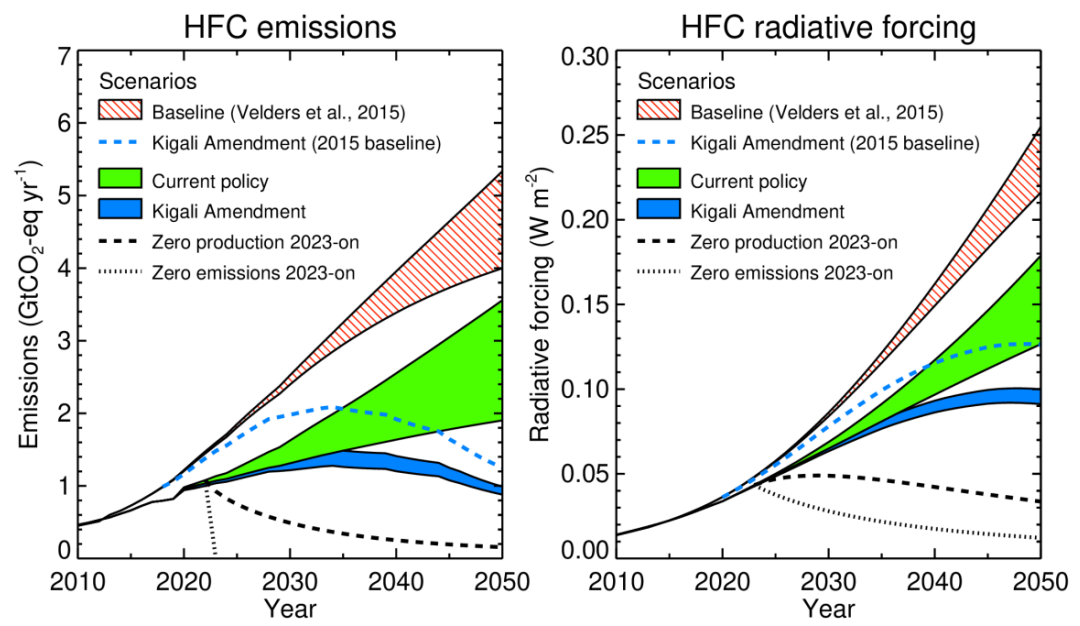

Figure 4: Global total HFC emissions $\left(\mathrm{GtCO}_{2}\right.$-eq $\left.\mathrm{yr}^{-1}\right)$ (left panel) and radiative forcing (right panel) from the 2015 baseline scenario and the "current policy" scenario. The bands represent the upper and lower ranges of these scenarios. Also shown are scenarios that follow the phasedown schedules of the 2016 Kigali Amendment, based on the 2015 baseline, and the "current policy" scenario. Also shown are hypothetical scenarios in which the global HFC production ceases in 2023 or the global HFC emissions (from new production and from banks) cease in 2023. The curves contain the contributions of all HFCs except HFC-23. 
HFC-32
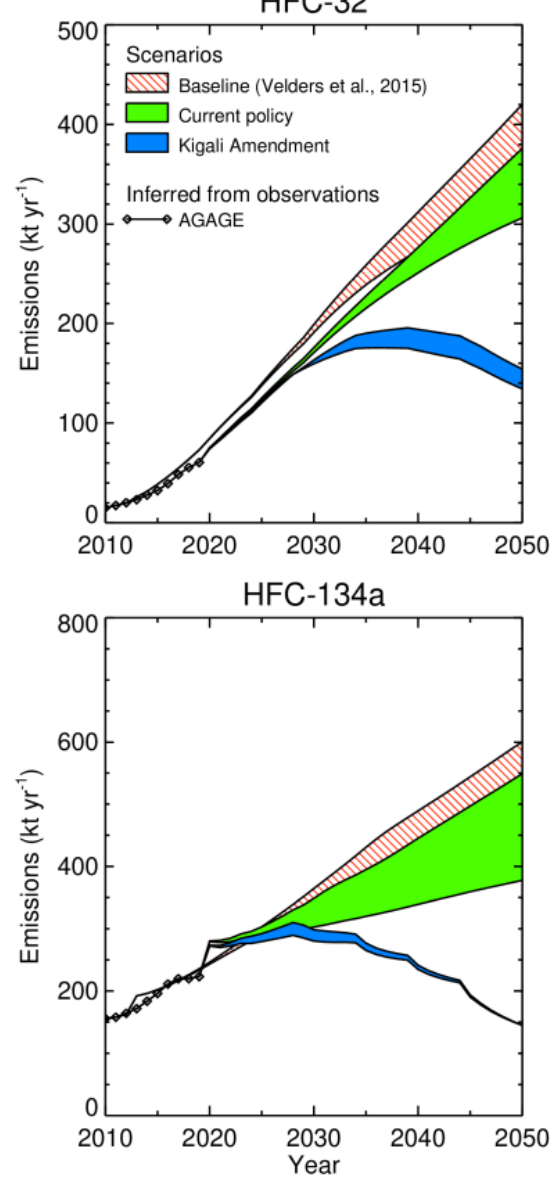

HFC-125
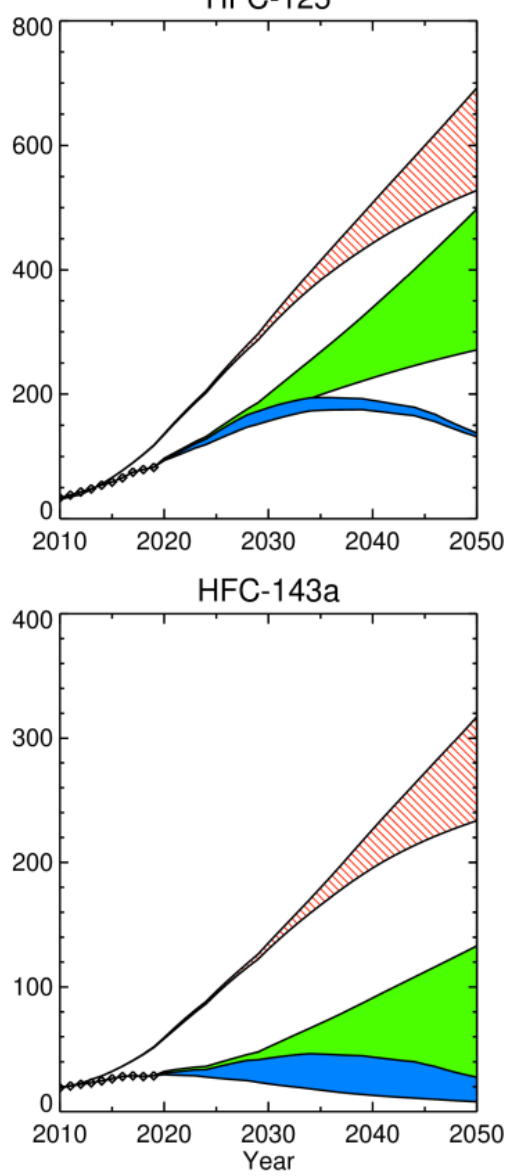

Figure 5: Global total emissions ( $\mathrm{kt} \mathrm{yr}^{-1}$ ) of HFC-32, HFC-125, HFC-134a, and HFC-143a from the 2015 baseline scenario, the "current policy" scenario, and the Kigali Amendment scenario. The bands represent the upper and lower ranges of these scenarios. Also shown the emissions inferred from observed mixing ratios from the AGAGE network. 

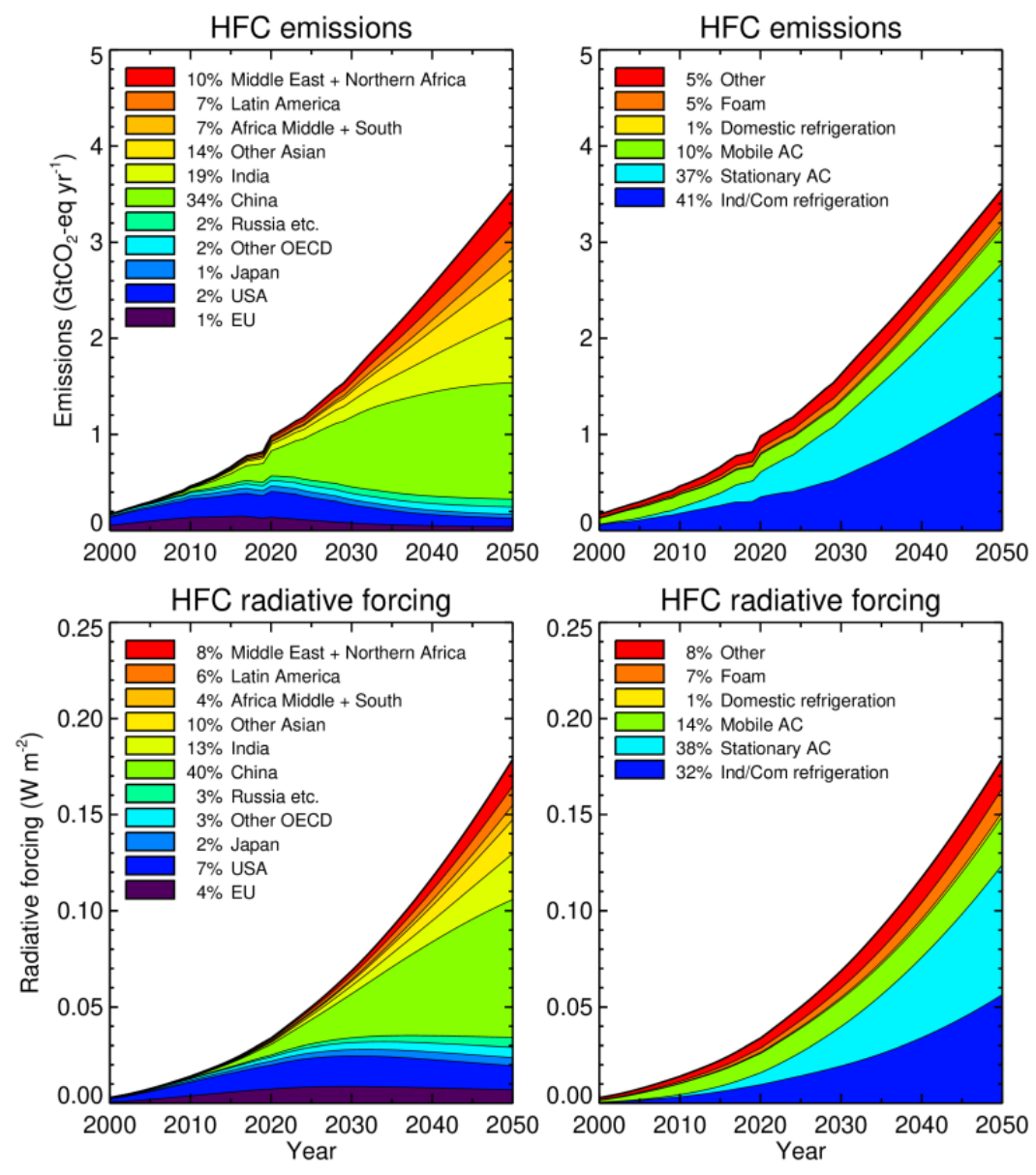

Figure 6: Global total $\mathrm{HFC}$ emissions $\left(\mathrm{GtCO}_{2}-\mathrm{eq}^{-1}\right)$ (top panels) and radiative forcing (bottom panels) from the upper range of the "current policy" scenario. Shown are the contributions from the different regions (left) and different sectors (right). The percentages refer to the relative contributions of the $\mathrm{CO}_{2}$-eq emissions and radiative forcing in the upper range in 2050 . 


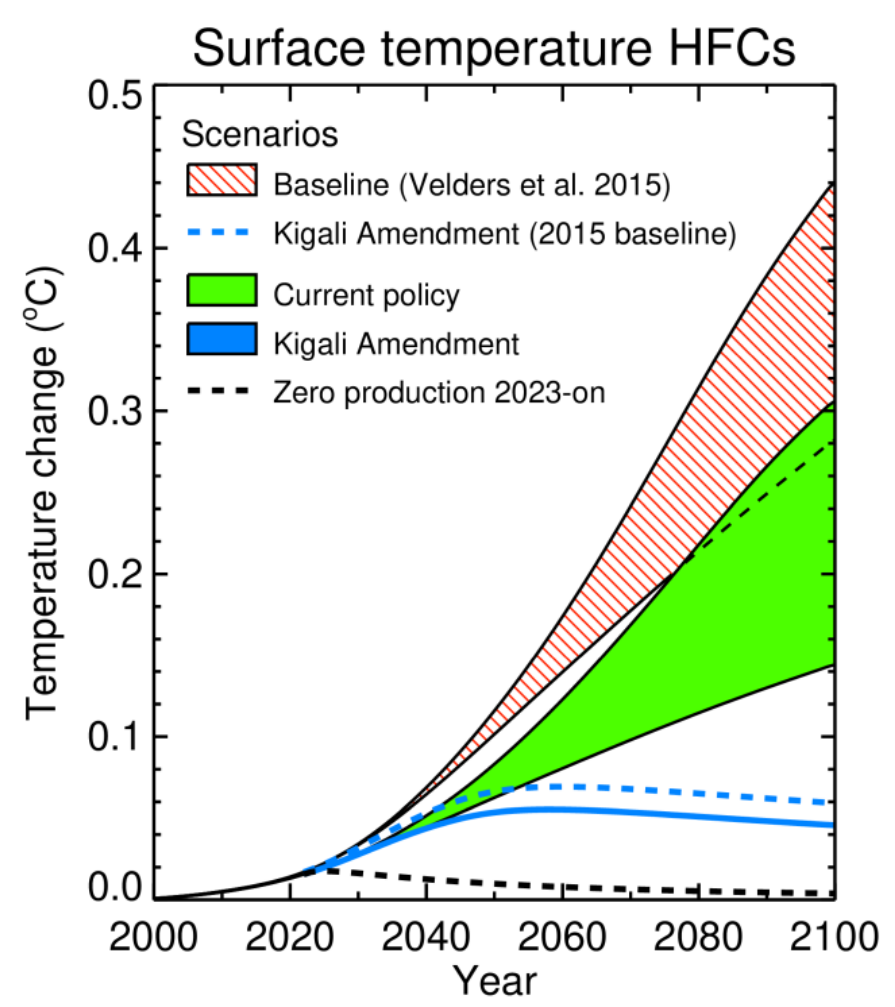

745 Figure 7: Contribution of HFCs to the global average surface warming for the 2015 baseline scenario without measures on HFC consumption and the "current policy" scenario. The bands represent the upper and lower ranges of these scenarios. Also shown are the effects of the phasedown of HFCs following controls of the Kigali Amendment and a hypothetical scenario assuming that the global production of emissions of HFCs would cease in 2023. The surface

750 temperature change is calculated using the MAGICC6 model (Meinshausen et al., 2011a).

The curves contain the contributions of all HFCs, except HFC-23. 